\title{
Classical conditioning of the rabbit eyelid response with mossy fiber stimulation as the conditioned stimulus
}

\author{
JOSEPH E. STEINMETZ, DAVID G. LAVOND, and RICHARD F. THOMPSON \\ Stanford University, Stanford, California
}

\begin{abstract}
The nictitating membrane responses of 12 rabbits were classically conditioned using mossy fiber stimulation as a conditioned stimulus (CS) and airpuff as an unconditioned stimulus. The dorsolateral pontine nucleus and the lateral reticular nucleus were effective stimulation-CS sites for learning. Robust conditioned responses were obtained with relatively few paired trials and extinguished with subsequent CS-alone presentations. In addition, explicitly unpaired presentations of stimulation and airpuff failed to produce response increments. These results support previous theories of cerebellar function that have proposed that mossy fibers supply "learning" input to the cerebellum for motor learning.
\end{abstract}

Recent lesion, recording, stimulation, and pharmacological studies have identified the cerebellar interpositus nucleus as an essential portion of the circuitry necessary for acquisition and retention of the classically conditioned eyelid response (Lavond, Hembree, \& Thompson, 1985; Mamounas, Madden, Barchas, \& Thompson, 1983; McCormick, Clark, Lavond, \& Thompson, 1982; McCormick \& Thompson, 1984b). This finding supports previous theories of cerebellar function that have suggested that the cerebellum is involved in motor learning (Albus, 1971; Brindley, 1964; Eccles, 1977; Gilbert, 1974; Grossberg, 1969; Ito, 1968, 1984; Marr, 1969). In brief, these theories have proposed that climbing fiber input to the cerebellar cortex may modify the effects of mossy fiber/parallal fiber input to the dendrites of Purkinje cells. Even though these models specify cerebellar cortex as the locus of plasticity, there is reason to believe that a similar interaction between climbing and mossy/ parallel fibers could exist in the cerebellar nuclei, since these nuclei receive direct projections of both fiber types (Beitz, 1976; Chan-Palay, 1977; Courville, Augustine, \& Martel, 1977; Courville \& Coulombe, 1977; Matsushita \& Ikeda, 1970, 1976; McCrea, Bishop, \& Kitai, 1977).

In agreement with models of cerebellar involvement in motor learning, we recently have obtained evidence that climbing fibers indeed supply "teaching" or "reinforcing" input to the cerebellum during classical eyelid conditioning. When climbing fiber input to the cerebellum was disrupted by lesions of the rostromedial portion of

This work was supported by National Institute of Mental Health Fellowship F32-MH08994 to J. E. Steinmetz, and by grants to R. F. Thompson, including National Science Foundation Grant BNS-8106648, Office of Naval Research Grant N00014-83-K-0238, and a Sloan Foundation grant. Reprint requests should be sent to: Richard F. Thompson, Department of Psychology, Stanford University, Stanford, CA 94305. the dorsal accessory olive (RM-DAO), a gradual decrement in the number and amplitude of the conditioned responses of well-trained animals was seen, even though paired training was continued (McCormick, Steinmetz, \& Thompson, in press; Steinmetz, McCormick, Baier, \& Thompson, 1984). The rate of conditioned response (CR) decrement was nearly identical to extinction rates of well-trained animals placed on CS-alone training. In addition, Mauk and Thompson (1984) reported that conditioned eyelid responses (and other discrete learned responses as well) can be obtained when a tone is used as a conditioned stimulus (CS) and direct electrical RMDAO stimulation is used as an unconditioned stimulus (US). The rate of acquisition of RM-DAO-stimulated animals was very similar to the acquisition rate of animals given tone(CS)-airpuff(US) training. Furthermore, interpositus lesions abolished both conditioned and unconditioned responses of animals previously trained with tone CS and RM-DAO-stimulation US. These studies strongly suggest that necessary " teaching"' information concerning US presentation is projected to the cerebellum via climbing fibers that arise from the RM-DAO.

The present paper is an initial report of successful eyelid conditioning when electrical stimulation of mossy fiber input to the cerebellum was used as a CS. The sites of mossy fiber stimulation included the dorsolateral pontine nucleus (DLPN) and the lateral reticular nucleus (LRN).

\section{METHOD}

Twelve male New Zealand albino rabbits were used in the present study. Insulated, bipolar electrodes (300-500- $\mu$ exposed tips) separated by $1 \mathrm{~mm}$ were implanted, under halothane (2\%-3\%) or ketamine-rompun anesthesia, in the region of either the right DLPN $(n=6)$ or the left LRN $(n=6)$. In addition to stereotaxic placement criteria, electrodes were positioned to maximize field potentials generated in cerebellar cortex by single-pulse, mossy fiber stimulation. After a 1-week recovery period, classical conditioning of the left nictitating membrane (NM) response 
was begun. Conditioning was achieved by pairing a 350-msec train of bipolar brain stimulation (the CS) with a coterminating 100 -msec airpuff (the US) directed at the left cornea and measuring $2.1 \mathrm{~N} / \mathrm{cm}^{2}(3 \mathrm{psi})$ at the source. DLPN and LRN stimulation was a $200-\mathrm{Hz}$ train of 0.1 msec constant-current pulses. DLPN stimulation was set at $60 \mu \mathrm{A}$, whereas LRN stimulation ranged from 60 to $120 \mu \mathrm{A}$. No discernible movements were observed at these stimulation intensities. Movements of the NM were monitored by connecting a minitorque potentiometer to a suture placed in the NM during surgery.

All animals initially received daily sessions of 108 training trials within a sound-isolation chamber. Each session was composed of 12 blocks, and each block contained 1 CS-alone presentation followed by 8 paired CS-US trials. Intertrial intervals were psuedorandomized with a range of 20-40 sec (mean $=30 \mathrm{sec})$. Animals were trained to a criterion (eight conditioned responses on 9 consecutive trials) and overtrained with an additional session. Rabbits were next given four daily sessions of CSalone extinction training (108 stimulation-alone presentations per day), and then two daily sessions of explicitly unpaired presentations of the stimulation CS and airpuff US (54 pseudorandomized presentations of each stimulus, with a mean interstimulus interval of $30 \mathrm{sec}$ ). Finally, all animals were retrained using standard paired trials to ensure that the electrical brain stimulus could still serve as an effective CS.

After training, the rabbits were sacrificed with an overdose of sodium pentobarbital, the stimulation site was marked by passing 100 $200 \mu \mathrm{A}$ of direct current for $10 \mathrm{sec}$, and the brain was perfused with saline followed by $10 \%$ Formalin. The brains were embedded in albumin, sectioned at $80 \mu$, and stained with cresyl violet for Nissl bodies and potassium ferrocyanide for the iron deposits left by the marking lesion.

\section{RESULTS}

Pairing a brain-stimulation CS with an airpuff US produced relatively rapid and robust conditioning in both groups of stimulated animals. DLPN animals demonstrated a significant acquisition effect as measured by $\mathrm{CR}$ amplitude $[\mathrm{F}(2,10)=7.00, \mathrm{p}<.05]$ and by percent $\mathrm{CRs}$ $[F(2,10)=28.80, p<.01]$. Likewise, significant increases in $\mathrm{CR}$ amplitude $[\mathrm{F}(2,10)=6.21, \mathrm{p}<.05]$ and percent $\operatorname{CRs}[F(2,10)=15.88, p<.01]$ were observed in LRN animals during paired training. DLPN rabbits' average number of trials to criterion was 99 , whereas LRN animals reached criterion after 71 trials. Percent CRs on

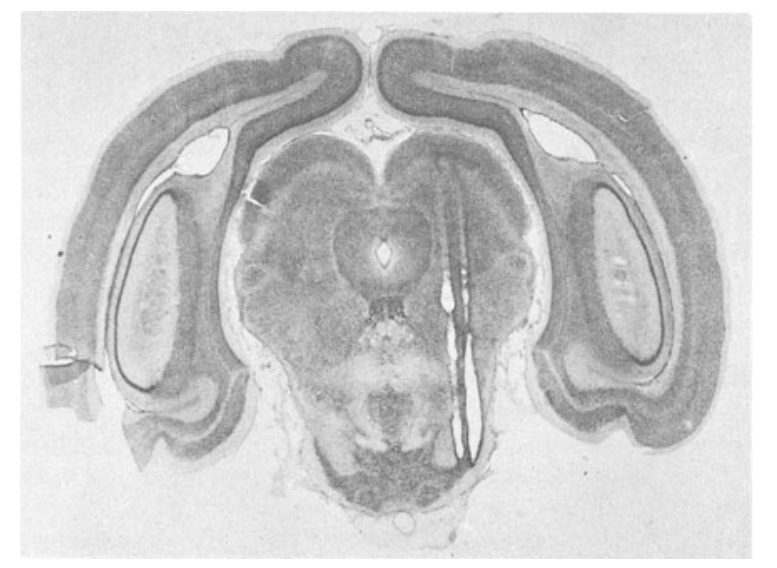

Figure 1. Photomicrograph of bipolar, stimulating electrode placement within the right dorsolateral pontine nucleus (DLPN).

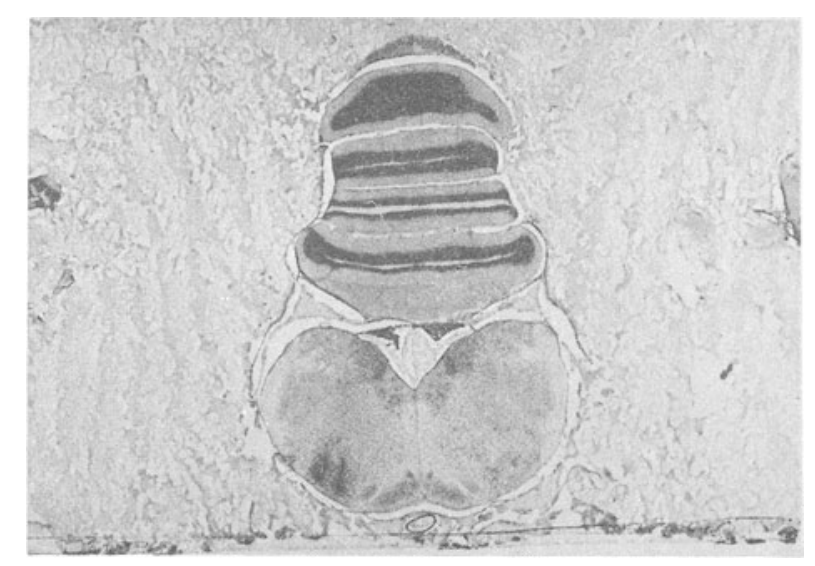

Figure 2. Photomicrograph of bipolar, stimulating electrode placement within the left lateral reticular nucleus (LRN).

the overtraining day were $89.7 \%$ for DLPN animals and $90.8 \%$ for LRN animals.

Significant decreases in $\mathrm{CR}$ amplitude $[\mathrm{F}(5,25)=3.18$, $\mathrm{p}<.05]$ and percent $\mathrm{CRs}[\mathrm{F}(5,25)=4.69, \mathrm{p}<.01]$ were observed in DLPN animals over extinction training, with average percent CRs dropping near baseline levels (mean $=12.9 \%$ ) on the last day of unpaired training. Similarly, LRN animals showed significant decrements in $\mathrm{CR}$ amplitude $[\mathrm{F}(5,25)=4.44, \mathrm{p}<.01]$ and percent $\mathrm{CRs}[\mathrm{F}(5,25)=8.71, \mathrm{p}<.01]$ during extinction. Average percent CRs was $17.6 \%$ on the last day of unpaired training in the LRN rabbits. Varying amounts of spontaneous recovery could be seen in both groups on early trials of CS-alone Sessions 1, 2, and 3. Unpaired presentations of CS and US did not produce increases in the amplitude or number of CRs, thus ruling out the possibility that response increases seen during acquisition training were due to nonassociative factors such as sensitization. Finally, when paired training was given after the unpaired sessions, all animals relearned rapidly, demonstrating that the electrical brain stimulus still served as an effective CS.

Examination of stimulation sites revealed electrode placement in or very near the DLPN or LRN. It therefore seems likely that the stimulation CSs used in the present study invaded at least a portion of these nuclei during the training process. See Figures 1 and 2 for representative electrode placements.

\section{DISCUSSION}

The present study demonstrated robust classical conditioning of the rabbit eyelid response when direct mossy fiber stimulation was used as a CS. Extinction training data indicated that response increments observed during acquisition were specific to stimulus pairing and were not due to nonassociative processes such as sensitization. Presentations of CS-alone trials produced gradual response decrements over sessions, with spontaneous recovery evident on early trials of each session. Furthermore, no response increments were observed during the two unpaired sessions that followed CS-alone extinction. These data suggest 
that eyelid conditioning obtained with a mossy fiber stimulation CS is behaviorally identical to conditioning that develops when standard CSs such as tones and lights are used.

There have been previous reports of successful conditioning with brain stimulation as a CS. Doty, Rutledge, and Larsen (1956) successfully conditioned the cat foreleg flexion response using several stimulation sites in the cerebral cortex (e.g., the ectosylvian, middle suprasylvian, postlateral, and marginal gyri). Neilson, Knight, and Porter (1962) delivered a stimulation CS to a variety of subcortical structures (e.g., caudate nucleus, reticular nucleus, and superior colliculus) and effectively conditioned a forepaw shock avoidance response. (We have shown that the cerebellar interpositus nucleus is also essential for hindlimb flexion conditioning in the rabbit-Donegan, Lowry, \& Thompson, 1983). Similarly, Patterson $(1970,1971)$ reported that stimulation of the inferior colliculus can serve as an effective CS for conditioning the rabbit NM response. It is important to note that many of these effective CS stimulation sites project directly to pontine nuclei that in turn, project to the cerebellum as mossy fiber inputs. There is ample evidence that the DLPN receives projections from the inferior and superior colliculi and from auditory cortex (Brodal, 1972; Kawamura \& Brodal, 1973). Similarly, the LRN is known to receive fibers from the cerebral cortex (Brodal, Marsala, \& Brodal, 1967; Künzle \& Wiesendanger, 1974; Kuypers, 1958a, 1958b, 1958c; Walberg, 1958), as well as from the superior colliculi (Kawamura, Brodal, \& Hoddevik, 1974) and red nucleus (Courville, 1966; Edwards, 1972; Hinman \& Carpenter, 1959; Mizuno, Mochizuki, Akimoto, Matsushima, \& Nakamura, 1973; Walberg, 1958). We suggest that brain stimulation sites used in previous studies may have produced conditioned responses by activating mossy fibers. Indeed, the only difference between the earlier brain stimulation studies and the present study may be that DLPN and LRN stimulation CSs directly activate the mossy fiber pathway into the cerebellum during conditioning.

Preliminary data from our laboratory suggest that conditioned responses produced by pairing direct stimulation of mossy fibers (e.g., the DLPN) with an airpuff are critically dependent on the cerebellum. Lesions of the interpositus nuclei severely impaired conditioned responding in one well-trained animal and completely abolished the conditioned responses of a second well-trained animal-a result consistent with previous studies in which interpositus lesions abolished eyelid conditioning established with tone-airpuff pairings (Lavond et al., 1985; McCormick et al., 1982). There are differences between the DLPN and LRN in the patterns of their respective cerebellar projections. Anatomical studies indicate that the DLPN projects heavily to cerebellar cortex, with fewer projections to the cerebellar nuclei (see Bloedel \& Courville, 1981, for review). Conversely, it appears that the LRN projects heavily to the dentate and interpositus nuclei, with fibers also reaching the cerebellar cortex (Brodal, 1975; Chan-Palay, 1977; Künzle, 1975; Matsushita \& Ikeda, 1976; McCrea et al., 1977). Both nuclei project mossy fibers bilaterally, thus providing both sides of the cerebellum with information concerning the CS.

In agreement with theories of cerebellar involvement in motor learning (Albus, 1971; Brindley, 1964; Eccles, 1977; Gilbert, 1974; Grossberg, 1969; Ito, 1968, 1984; Marr, 1969), the present data demonstrate that mossy fibers can provide critical "CS" information to the cerebellum necessary for conditioning. Results of previous studies in our laboratory support the hypothesis that the essential memory trace(s) for eyelid conditioning and learning of other discrete behavioral responses are established in the cerebellum and /or in structures afferent to the cerebellum for which the cerebellum is a mandatory efferent (e.g., Clark, McCormick, Lavond, \& Thompson, 1984; Lavond, McCormick, Clark, Holmes, \& Thompson, 1981; Lavond, McCormick, \& Thompson, 1984; McCormick et al., 1982; McCormick et al., 1981; McCormick \& Thompson, 1984a, 1984b; Thompson et al., 1984). The present result, that activation of mossy fiber projections to the cerebellum is an effective CS, together with our results indicating that the climbing fiber projection from the inferior olive appears to be the necessary and sufficient "teaching"' or "reinforcing" input (Mauk \& Thompson, 1984; McCormick et al., in press; Steinmetz et al., 1984) support the hypothesis that essential memory traces are established in the cerebellum.
Our previous lesion studies have indicated that the interpositus nucleus is essential for retention of the eyelid (and leg flexion) learned responses established with peripheral stimuli, but that the cerebellar cortex is not essential (at least for the learned eyelid response) (Clark et al., 1984; Lavond et al., 1985; McCormick \& Thompson, 1984a, 1984b). However, our electrophysiological recording studies are consistent with the view that, if the memory traces are indeed established in the cerebellum, they may in fact be established in both the cerebellar cortex and the interpositus nucleus (McCormick \& Thompson, 1984b), a possibility that is consistent with our lesion results. We therefore suggest as a working hypothesis that under normal conditions of learning with peripheral stimuli: (1) The essential CS information is projected to the cerebellum via mossy fibers; (2) the essential teaching or reinforcing information from the US is projected to the cerebellum via climbing fibers from the inferior olive; and (3) memory traces are established in highly localized regions in the cerebellar cortex and interpositus nucleus at loci of convergence of the critical mossy and climbing fiber projections. If this is indeed the case, then it could be hypothesized that training induces either increased (the Marr, 1969, hypothesis) or decreased (the Albus, 1971, hypothesis) responsiveness to the CS in those Purkinje cells projecting to critical interpositus neurons. Ito (1984; Ito, Sakurai, \& Tongroach, 1982) has reported that conjunctive stimulation of mossy fibers (vestibular nerve) and climbing fibers (inferior olive) in the high-decerebrate rabbit causes a persisting decrease in excitability of Purkinje cells in the flocculus activated by stimulation of the vestibular nerve, due apparently to a change in parallel fiber-Purkinje cell synapses.

Use of direct mossy fiber stimulation as a CS apparently provides a well-controlled methodology to aid in identifying the cerebellar circuit necessary and sufficient for the learning and memory of discrete, adaptive somatic responses. Given the differential projection sites of the DLPN and the LRN, it is possible that cerebellar cortex might be essential when stimulation of the DLPN, but not the LRN, is used as the CS.

\section{REFERENCES}

Albus, J. S. (1971). A theory of cerebellar function. Mathematical Bioscience, 10, 25-61.

BEITZ, A. J. (1976). The topographical organization of the olivo-dentate and dentato-olivary pathways in the cat. Brain Research, 115, 311-317.

Bloedel, J. R., \& Courville, J. (1981). Cerebellar afferent systems. In J. M. Brookhart, V. B. Mountcastle, \& V. B. Brooks (Eds.), Handbook of physiology, Section 1: The nervous system: Vol 2. Motor control (pp. 735-830). Baltimore, MD: Williams and Wilkins.

BRINDLEY, G. S. (1964). The use made by the cerebellum of the information that it receives from sense organs. International Brain Research Organization Bulletin, 3, 30.

BroDAL, P. (1972). The corticopontine projection in the cat: The projection from the auditory cortex. Archives of Italian Biology, 110, 119-144.

Brodal, P. (1975). Demonstration of a somatotopically organized projection onto the paramedian lobule and the anterior lobe from the lateral reticular nucleus: An experimental study with the horseradish peroxidase method. Brain Research, 95, 221-239.

Brodal, P., Marsala, J., \& Brodal, A. (1967). The cerebral cortical projection to the lateral reticular nucleus in the cat with special reference to the sensorimotor cortical areas. Brain Research, 6, 252-274.

Chan-Palay, V. (1977). Cerebellar dentate nucleus: Organization, cytology, and transmitters. Berlin: Springer.

Clark, G. A., McCormick, D. A., Lavond, D. G., \& Thompson, R. F. (1984). Effects of lesions of cerebellar nuclei on conditioned behavioral and hippocampal neuronal responses. Brain Research, 291, 125-136.

Courville, J. (1966). Rubrobulbar fibers to the facial nucleus and the lateral reticular nucleus (nucleus of the lateral funiculus): An experimental study in the cat with silver impregnation methods. Brain Research, 1, 317-337. 
Courville, J., Augustine, J. R., \& Martel, P. (1977). Projections from the inferior olive to the cerebellar nuclei in the cat demonstrated by retrograde transport of horseradish peroxidase. Brain Research, 130, 405-419.

Courville, J., \& Coulombe, G. (1977). Pontine projection to cerebellar cortex and nuclei. Neuroscience Abstracts, 3, 56.

Donegan, N. H., Lowry, R. W., \& Thompson, R. F. (1983). Effects of lesioning cerebellar nuclei on conditioned leg-flexion responses. Neuroscience Abstracts, 9, 331.

Doty, R. W., RutLEDGE, L. T., \& LARSEN, R. M. (1956). Conditioned reflexes established to electric stimulation of cat cerebral cortex. Journal of Neurophysiology, 19, 401-415.

ECCLES, J. C. (1977). An instruction-selection theory of learning in the cerebellar cortex. Brain Research, 127, 327-352.

EDWARDS, S. B. (1972). The ascending and descending projections of the red nucleus in the cat: An experimental study using an autoradiographic tracing method. Brain Research, 48, 45-63.

GilberT, P. F.C. (1974). A theory of memory that explains the function and structure of the cerebellum. Brain Research, 70, 1-18.

GrossBerG, S. (1969). On learning of spatiotemporal patterns by networks with ordered sensory and motor components: I. Excitatory components of the cerebellum. Studies of Applied Mathematics, 48, 105-132.

Hinman, A., \& Carpenter, M. B. (1959). Efferent fiber projections of the red nucleus in the cat. Journal of Comparative Neurology, 113, 61-82.

Iто, M. (1968). Neurophysiological aspects of the cerebellar motor control system. International Journal of Neurology, 7, 162-176.

Iто, M. (1984). The cerebellum and neural control. New York: Raven Press.

Ito, M., Sakurai, M., \& Tongroach, P. (1982). Climbing fibre induced depression of both mossy fibre responsiveness and glutamate sensitivity of cerebellar Purkinje cells. Journal of Physiology, 324, 113-134.

KaWAmura, K. , \& Brodal, A. (1973). The tectopontine projection in the cat: An experimental anatomical study with comments on pathways for teleceptive impulses to the cerebellum. Journal of Comparative Neurology, 149, 371-390.

Kawamura, K., Brodal, A., \& HoddeviK, F. (1974). The projection of the superior colliculus onto the reticular formation of the brain stem: An experimental anatomical study in the cat. Experimental Brain Research, 19, 1-19.

KÜNZLE, H. (1975). Autoradiographic tracing of the cerebellar projections from the lateral reticular nucleus of the cat. Experimental Brain Research, 22, 255-266.

KüNZle, H., \& Wiesendanger, M. (1974). Pyramidal connections to the lateral reticular nucleus in the cat: A degeneration study. Acta Anatomica (Basel), 88, 105-114.

KUYPERS, H. G. J. M. (1958a). An anatomical analysis of cortico-bulbar connexions to the pons and lower brainstem in the cat. Journal of Anatomy (London), 92, 198-218.

KUYPERS, H. G. J. M. (1958b). Cortico-bulbar connexions to the pons and lower brainstem in man: An anatomical study. Brain, 81, 364-388.

KUYPERS, H. G. J. M. (1958c). Some projections from the peri-central cortex to the pons and lower brainstem in monkey and chimpanzee. Journal of Comparative Neurology, 110, 221-255.

LAvond, D. G., Hembree, T. L., \& ThOMPSON, R. F. (1985). Effect of kainic acid lesions of the cerebellar interpositus nucleus on eyelid conditioning in the rabbit. Brain Research, 326, 179-182.

Lavond, D. G., McCormick, D. A., Clark, G. A., Holmes, D. T., \& THOMPSON, R. F. (1981). Effects of ipsilateral rostral pontine reticular lesions on retention of classically conditioned nictitating membrane and eyelid responses. Physiological Psychology, 9, 335-339.

Lavond, D. G., McCormick, D. A., \& Thompson, R. F. (1984). A nonrecoverable learning deficit. Physiological Psychology, 12, 103-110.
Mamounas, L. A., Madden, J., IV, Barchas, J. D., \& Thompson, R. F. (1983). Microinfusion of GABA antagonists into the cerebellar deep nuclei selectively abolishes the classically conditioned eyelid response in the rabbit. Neuroscience Abstracts, 9, 830.

MARR, D. (1969). A theory of cerebellar cortex. Journal of Physiology (London), 202, 437-470.

MAtsushita, M., \& IKEDA, M. (1970). Olivary projections to the cerebellar nuclei in the cat. Experimental Brain Research, 10, 488-500.

Matsushita, M., \& IKEDA, M. (1976). Projections from the lateral reticular nucleus to the cerebellar cortex and nuclei in the cat. Experimental Brain Research, 24, 403-421.

Mauk, M. D., \& Thompson, R. F. (1984). Classical conditioning using stimulation of the inferior olive as the unconditioned stimulus. Neuroscience Abstracts, 10, 122.

McCormick, D. A., Clark, G. A., Lavond, D. G., \& Thompson, R. F. (1982). Initial localization of the memory trace for a basic form of learning. Proceedings of the National Academy of Sciences, 79, 2731-2735.

McCormick, D. A., Lavond, D. G., Clark, G. A., Kettner, R. E., Rising, C. E., \& ThOMPSON, R. F. (1981). The engram found? Role of the cerebellum in classical conditioning of nictitating membrane and eyelid responses. Bulletin of the Psychonomic Society, 18, 103-105.

McCormick, D. A., Steinmetz, J. E., \& Thompson, R. F. (in press). Lesions of the inferior olivary complex cause extinction of the classically conditioned eyeblink response. Brain Research.

McCormick, D. A., \& Thompson, R. F. (1984a). Cerebellum: Essential involvement in the classically conditioned eyelid response. Science, 223, 296-299.

McCormick, D. A., \& Thompson, R. F. (1984b). Neuronal responses of the rabbit cerebellum during acquisition and performance of a classically conditioned nictitating membrane-eyelid response. Journal of Neuroscience, 4, 2811-2822.

McCrea, R. A., Bishop, G. A., \& Kitai, S. T. (1977). Electrophysiological and horseradish peroxidase studies of precerebellar afferents to the nucleus interpositus anterior: II. Mossy fiber system. Brain Research, 122, 215-218.

Mizuno, M., Mochizuki, K., Akimoto, C., Matsushima, R., \& NAKAMURA, Y. (1973). Rubrobulbar projections in the rabbit: A light and electron microscopic study. Journal of Comparative Neurology, 147, 267-280.

Neilson, H. C., Knight, J. M., \& Porter, P. B. (1962). Subcortical conditioning, generalization, and transfer. Journal of Comparative and Physiological Psychology, 55, 168-173.

Patterson, M. M. (1970). Classical conditioning of the rabbit's (Oryctolagus cuniculus) nictitating membrane response with fluctuating ISI and intracranial CS. Journal of Comparative and Physiological Psychology, 72, 193-202.

Patterson, M. M. (1971). Inferior collicular CS intensity effect on rabbit nictitating membrane conditioning. Physiology \& Behavior, 6, 273-278,

Steinmetz, J. E., McCormick, D. A., Baier, C. A., \& Thompson, R. F. (1984). Involvement of the inferior olive in classical conditioning of the rabbit eyelid. Neuroscience Abstracts, 10, 122.

Thompson, R. F., Clark, G. A., Donegan, N. H., Lavond, D. G., Madden, J. IV, Mamounas, L. A., Mauk, M. D., \& McCormick, D. A. (1984). Neuronal substrates of basic associative learning. In L. Squire \& N. Butters (Eds.), Neuropsychology of memory (pp. 424442). New York: Guilford Press.

W ALBERG, F. (1958). Descending connections to the lateral reticular nucleus: An experimental study in the cat. Journal of Comparative Neurology, 109, 363-390.

(Manuscript received for publication December 28, 1984.) 